\title{
Evaluating \\ Insecticide \\ Application \\ Techniques to \\ Control Aphids in Vegetable Leaf Crops
}

\author{
Celeste Welty ${ }^{1}$, Sandra Alcaraz', \\ and H. Erdal Ozkan ${ }^{2}$
}

Additional index words. nozzles, sprayers, collards, mustard greens, turnip greens, lettuce, Myzus persicae

Summary. Insecticide application techniques were evaluated to find the most effective way to spray contact insecticides to control aphids on leaf crops under field conditions. A hydraulic boom sprayer was tested with several nozzle types, nozzle positions, and pressures, and compared with an electrostatic sprayer and a controlled droplet applicator (CDA). Spray deposition in the canopy and drift were evaluated with moisture-sensitive cards. Trials were conducted on collards and red leaf lettuce in 1989, mustard greens in 1990, and turnip greens in 1991. Green peach aphid [Myzus persicae (Sulzer)] was the major species in all trials. Among hydraulic boom treatments in all trials, aphid control was not significantly different when insecticide applied at $60 \mathrm{psi}(414 \mathrm{kPa})$ was delivered by hollow cone, twin

${ }^{1}$ Department of Entomology, The Ohio State University, ${ }^{2}$ Department of Agricultural Engineering, The Ohio State University.

We thank R. Hassell and K. Scaife for maintaining fields and applying treatments; $H$. Almekinders and $E$. Escallon for delivering electrostatic treatments; $R$. Sheapard for use of a CDA in 1990; B. Eisley for technical assistance; and S. St. Martin for statistical advice. Support from Rohm \& Haas Co. and the Ohio Fresh Market and Processing Vegetable Research Foundation, and materials provided by Spraying Systems Co., Grower Service Corp., and Ciba Geigy Co., are gratefully acknowledged. Salaries were partially provided by state and federal funds appropriated to the Ohio Agricultured Research and Development Center, Ohio State University. This article is OARDC Journal article no. 62-95, Reference to a proprietary product or company does not imply approval or recommendation of the product by the Ohio State University to the exclusion of others that may be suitable. The cost of publishing this paper was defrayed in part by the payment of page charges. Under postal regulations, this paper therefore must be hereby marked advertisement solely to indicate this fact. 
flat-fan, or standard flat-fan nozzles mounted directly on the boom. In most trials, hollow cones were more effective when mounted on drop pipes and directed sideways into rows than when mounted on the boom and directed over rows. Hollow cone nozzles used at $150 \mathrm{psi}$ (1035 kpa) vs. 60 psi did not control aphids significantly better, but higher pressure caused significantly more drift. Contact insecticide applied by an electrostatic sprayer controlled aphids somewhat less satisfactorily than by a conventional hydraulic sprayer. Insecticide applied by a CDA controlled aphids the same as by a hydraulic boom sprayer but with slightly less drift. The desired objective of maximum aphid control, good coverage of downward-facing surfaces in the canopy, and minimum drift was most consistently provided by the hydraulic boom sprayer with hollow cone nozzles on drop pipes directed sideways into the canopy using a pressure of 60 psi.

W hen decisions on the need to apply pesticides are based on scouting for target pests rather than on a calendar schedule. there is increased reliance on high efficacy from each treatment that is applied. Growers need information on how to suppress pests effectively and economically wit-h minimal drift on adjacent crop. A good example of where such information can contribute to better crop production is leafy vegetables, where insect pests must be carefully managed if high-quality leaves are to be harvested. In Ohio, leafcrops such as mustard greens [ Brassica juncea (L.) Czerniak],turnip greens (B. rapa L.), collards [B. oleracea var. acephala (L.) DC], and leaf lettuce (Lactuca sativa L. ) are attacked by a complex of aphids and caterpillars. Aphids cause less direct feeding damage than caterpillars, but aphids can be more troublesome to growers because aphids are difficult to control by conventional insecticide application. Most damage by aphids is cosmetic, but the presence of aphid bodies on foliage can cause buyers to reject the product. Severe aphid infestations can lead to plant death, particularly on young plants.

When aphid populations reach damaging levels on commercial leaf crops, insecticides such as dimethoate, endosulfan, diazinon. or malathion are usually applied. Dimethoate is a sys- temic insecticide that is preferred for controlling aphids during early crop stages, but it may not be used on leaf crops 14 days before harvest. The only aphicides with preharvest restrictions of $<14$ days and registered for use on these crops are the contact insecticides diazinon and malathion. Growers often complain of poor control achieved with these contact insecticides. Poor control may be due to insecticide resistance, incomplete coverage of plants by insecticide, or aphid resurgence after disruption of natural enemies. Resistance is not the likely cause of poor control because all contact insecticides tested adequately controled aphids on leaf crops in the same area in Ohio where complaints arose (Hoy et al., 1989a, 1989b, 1990). We suspect that inappropriate equipment or spraying techniques are often the cause of poor control.

The conventional equipment used by growers for spraying insecticides on leaf crops is a tractor-drawn hydraulic boom sprayer with hollow cone nozzles positioned over crop rows. Growers know that using high spray volume and high pressure should improve pest control, but they are usually reluctant to do this because spraying large volumes is time consuming and high pressure increases drift and causes off-target application. An alternative to positioning nozzles directly on the spray boom is putting nozzles on drop pipes so that they direct spray to undersides of leaves, but drop pipes are not commonly used by vegetable growers in Ohio. Information is needed on the relative benefits of altering pressure and nozzle position, while keeping volume constant.

Hollow cone nozzles are recommended for spraying foliage because droplets are sent to plants from different angles, while flat-fan nozzles are used for broadcast spraying because they produce a narrow plane spray pattern (Matthews, 1992). Although standard flat-fan nozzles are used by some growers for spraying foliar insecticides, the large droplets produced do not thoroughly cover the crop. At a given pressure and flow rate, droplets produced by hollow cones are smaller than those produced by flat-fans, and their small size allows better penetration into dense foliage (Marer, 1988). Although small droplets produced by hollow cones cover better, they are more susceptible to drift. Twin flat- fans are a relatively new nozzle type designed to distribute spray over a range of spray pressures, thus providing good spray penetration into the canopy. Twin flat-fans provide droplets smaller than those of a standard flat-fan; droplets are atomized by two small orifices that direct two flat spray patterns, one $30^{\circ}$ forwards and one $30^{\circ}$ backwards (Reed, 1988).

Alternatives to conventional hydraulic sprayers are controlled droplet applicators (CDAs) and electrostatic sprayers. Growers are not sure whether these new sprayers offer substantial advantages over conventional sprayers for applying insecticides. The relative advantages and disadvantages of these systems are being debated among scientists, as reviewed by Hislop (1987). Conventional hydraulic sprayers produce droplets from 50 to $500 \mu \mathrm{m}$ in diameter, with most in the middle range of 100 to $250 \mu \mathrm{m}$ (Marer, 1988). Most small droplets are lost by evaporation or deflection before they hit the target. A CDA, also known as a rotary atomizer, produces uniform droplets in a narrow size range by using centrifugal force to spin a disc or cup, which distributes the pesticide mixture through the disc's serrated edges; droplet size can be adjusted from 100 to $400 \mu \mathrm{m}$ through the CDA's rotational speed between 1000 and 6000 rpm (Marer, 1988). Applying insecticides with a CDA uses smaller volumes and results in less drift (Matthews, 1992). The CDA may lack enough downward force for good penetration and uniform coverage (Hislop, 1987), which would lead to poorer control when using contact insecticides to control aphids on leaf crops. Electrostatic sprayers use electrostatic forces of attraction to charge fine droplets that are attracted to target surfaces (Marer 1988). Sprays with electrostatic properties have reduced drift and need less active ingredient for acceptable control (Matthews, 1992). Electrostatic sprayers produce much smaller droplets than conventional hydraulic sprayers. The charged spray should increase coverage of bottom surfaces of leaves, which may be left untouched by other sprayer systems; this is relevant for aphid control because aphids prefer bottom surfaces.

Many reports have been published on physical differences in conventional and alternative spray systems, but studies that include biological evaluations 
Table 1. Summary of crop, plot size, crop height at time of treatment, spay date, and aphid evaluation method in six trials on aphid control.

\begin{tabular}{|c|c|c|c|c|c|c|c|}
\hline \multirow{3}{*}{$\begin{array}{l}\text { Trial } \\
\text { no. }\end{array}$} & \multirow[b]{3}{*}{ Crop (cultivar) } & \multirow{2}{*}{\multicolumn{2}{|c|}{ Plot size (m) }} & \multirow{3}{*}{$\begin{array}{c}\text { Crop } \\
\text { ht } \\
(\mathrm{cm})\end{array}$} & \multirow[b]{3}{*}{ Spray date } & \multicolumn{2}{|c|}{ Aphid evaluation } \\
\hline & & & & & & \multirow{2}{*}{$\begin{array}{c}\text { No. days } \\
\text { posttreatment }\end{array}$} & \multirow{2}{*}{$\begin{array}{c}\text { No. plants } \\
\text { per plot }\end{array}$} \\
\hline & & Length & Width & & & & \\
\hline 1 & Collards (Vates) & 40.2 & 4.6 & 46 & 24 Aug. 1989 & 4 & 4 \\
\hline 2 & Lettuce (Red Sails) & 13.4 & 7.6 & 30 & 8 Sept. 1989 & 3 & 4 \\
\hline 3 & Mustard (Green Wave) & 9.1 & 7.6 & 20 & 10 Aug. 1990 & 3,12 & 20,5 \\
\hline 4 & Mustard (Green Wave) & 9.1 & 4.6 & 36 & 10 Sept. 1990 & 2,7 & 10,5 \\
\hline 5 & Turnip (Seven Top) & 7.6 & 4.3 & 15 & 2 Oct. 1991 & $2,7,14$ & $20,20,20$ \\
\hline 6 & Turnip (Seven Top) & 7.6 & 4.3 & 46 & 25 Oct. 1991 & 3,7 & $20,20,20$ \\
\hline
\end{tabular}

have been far fewer. Publications on insecticide or fungicide spray systems under field conditions are scarce, despite the importance of spray coverage to control insects and diseases effectively. Biological evaluations of spray systems in the field have been reported for insecticides (Mistric and Smith, 1971; Womac et al., 1992; Zehnder and Speese, 1991) and fungicides (Cooke et al., 1990; Jeffers et al., 1982).

This research was done to find the most effective way to apply insecticide for controlling aphids on leaf crops under field conditions. The primary objective was to evaluate aphid control with an insecticide applied by a hydraulic boom sprayer with various nozzle types, nozzle positions, and pressures. Secondary objectives were to compare a hydraulic sprayer with CDA and electrostatic sprayers; measure canopy coverage for comparison with aphid ratings as an evaluation of treatment effects; measure drift associated with different application techniques; and evaluate the effect of nozzle type on efficacy of contact vs. systemic insecticides.

\section{Materials and methods}

Experimental design. In each of six trials, plots were arranged in a randomized complete-block design with four blocked replicates of each treatment. Crops, cultivars, plot dimensions, crop height at time of treatment, and treatment dates are shown in Table 1.

Experimental treatmemts. Spray parameters that were constant in all trials with hydraulic boom sprayers were a spray volume of 40 gal $\backslash$ acre (374 liters/ha) and a nozzle spacing of 20 inches $(50 \mathrm{~cm})$. Travel speed varied from 1.5 to 4 miles/h (2.4 to 6.4 $\mathrm{km} \cdot \mathrm{h}^{-1}$ ) to maintain a fixed spray volume per acre. Parameters that varied were nozzle type, nozzle position, and operating pressure. Nozzle types tested were disc-core hollow cones, one-piece hollow cones, standard flat fans, and twin-orifice (or double) flat fans. All nozzle equipment used was manufactured by Spraying Systems Co. (Wheaton, Ill.); specific nozzle tip models used are listed in Table 2. Flatfan nozzles had spray angles of $80^{\circ}$ or $110^{\circ}$; the distance between nozzles and the canopy was 17 inches $(42 \mathrm{~cm})$ for $80^{\circ}$ nozzles and 12 inches $(30 \mathrm{~cm})$ for $110^{\circ}$ nozzles. Flat-fan and twin flat-fan nozzles were used for broadcast application and hollow cone nozzles were used for directed spraying. Nozzle positions tested with hollow cone nozzles were over the rows and sideways between rows. For applications directed over rows, nozzles were placed on the boom without drop pipes. For applications directed sideways, two nozzles were placed per drop pipe and drop pipes were oriented between rows with each nozzle directed towards a row. Pressures tested were 60 psi (414 kPa), 100 psi (690 $\mathrm{kPa}), 150$ psi $(1035 \mathrm{kPa})$, or 200 psi $(1380 \mathrm{kPa})$. All trials included an untreated control treatment. Trial 5 included an additional control treatment with water alone, which was applied by hollow cone nozzles directed over rows at 60-psi.

The electrostatic sprayer (Terronics Development Corp., Elwood, Ind. ) had an output of 0.6 gal/acre (5.6 liters/ha) and volume median droplet (VMD ) size was 50 $\mu \mathrm{m}$ in 1990 and $200 \mu \mathrm{m}$ in 1991 (Almekinders et al., 1992; Escallon \& Tyner, 1988). The CDA (Aircone Atomizer, United Spray Technologies, Monticello, Ind.) was operated at 3000 $\mathrm{rpm}$ with an output of $3.6 \mathrm{gal} / \mathrm{rein}$ (13.6 liters/rein), which produced a droplet size range from 150 to $275 \mu \mathrm{m}$ VMD. The CDA used in this study was air-assisted and different than the morewell-known CDA manufactured by MIcron Co. The CDA we used has an inverted cup with a serrated edge with

Table 2. Specific node tip models used in each of six trials on aphid control.

\begin{tabular}{lccccc}
\hline Nozzle type & $\begin{array}{c}\text { Pressure, } \\
\text { psi (kPa) }\end{array}$ & $\begin{array}{c}\text { Nozzle } \\
\text { Position }\end{array}$ & $\begin{array}{c}\text { Tria } \\
\text { no. }\end{array}$ & Nozzle tip \\
\hline Disc-core hollow cone & 60 & $(414)$ & Over \& drop & 1,2 & TeeJet D3-45 \\
Disc-core hollow cone & 60 & $(414)$ & Over & 3,4 & TeeJet D3-45 \\
Disc-core hollow cone & $60(414)$ & Over & 5,6 & TeeJet D4-45 \\
Disc-core hollow cone & 60 & $(414)$ & Drop & 3,4 & TeeJet D2-23 \\
Disc-core hollow cone & $60(414)$ & Drop & 5 & TeeJet D3-45 \\
Disc-core hollow cone & $100(690)$ & Over \& drop & 1,2 & TeeJet D5-23 \\
Disc-core hollow cone & $150(1035)$ & Over & 5 & TeeJet D3-25 \\
Disc-core hollow cone & $150(1035)$ & Over & 3,4 & TeeJet D4-23 \\
Disc-core hollow cone & $150(1035)$ & Drop & 3,4 & TeeJet D2-13 \\
Disc-core hollow cone & $150(1035)$ & Drop & 5 & TeeJet D3-23 \\
Disc-core hollow cone & $200(1380)$ & Over \& drop & 1,2 & TeeJet D15-25 \\
One-piece hollow cone & $60(414)$ & Drop & 1,2 & ConeJet TX10 \\
One-piece hollow cone & $100(690)$ & Over & 1,2 & ConeJet TX8 \\
Twin-orifice flat-fan & $60(414)$ & Broadcast & $1,2,3,4$ & TwinJet 8003 \\
Twin-orifice flat-fan & $60(414)$ & Broadcast & 5 & TwinJet 8004 \\
Standard flat-fan, 80 & $60(414)$ & Broadcast & 1,2 & TeeJet 8003 \\
Standard flat-fan, 110 & $60(414)$ & Broadcast & 1,2 & TeeJet 11003 \\
Sandard flat-fan, 80 & $60(414)$ & Broadcast & 5 & TeeJet 8004 \\
\hline
\end{tabular}




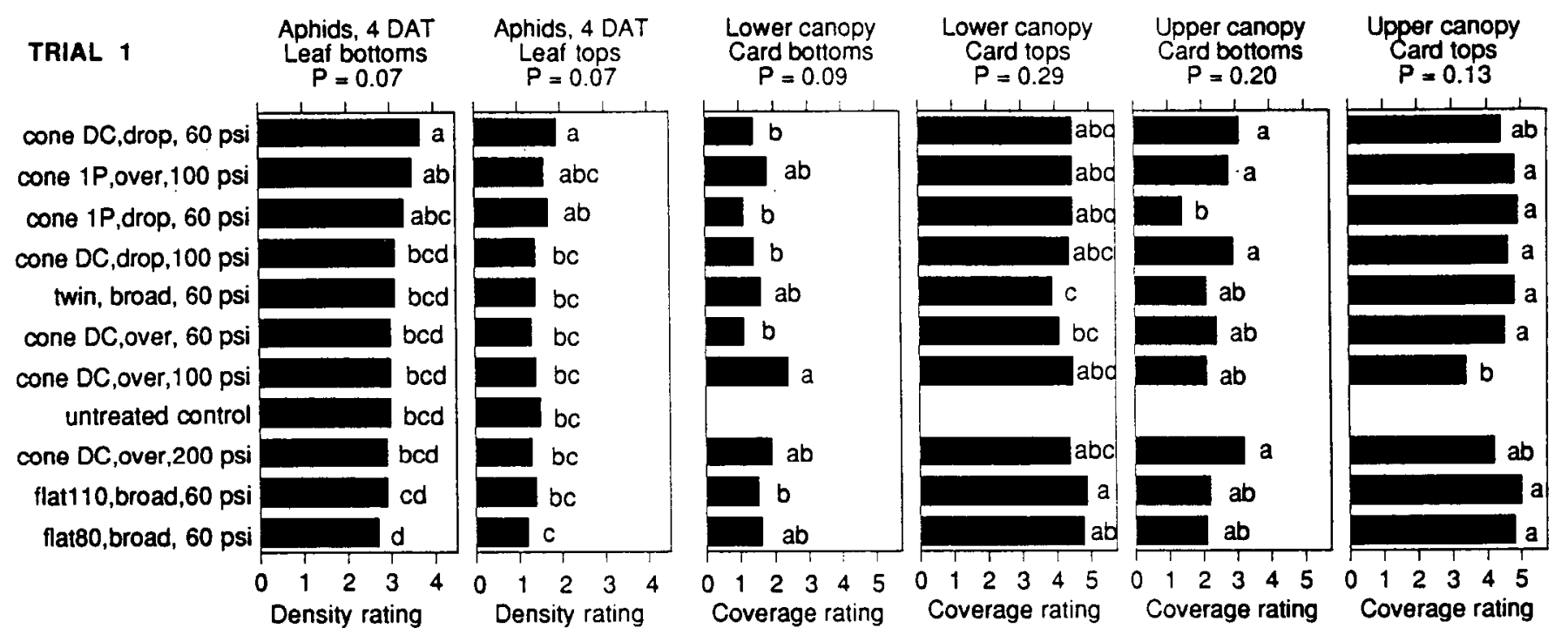

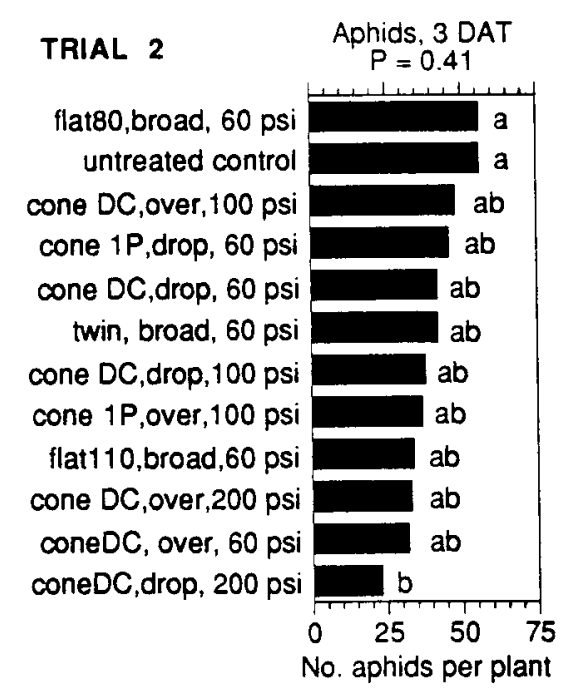

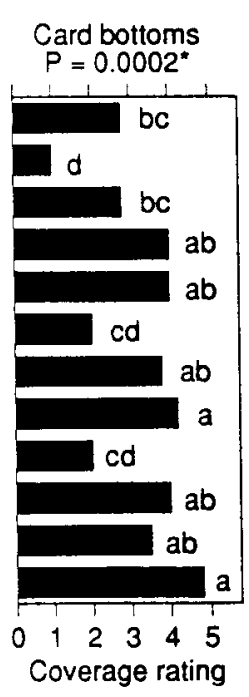

a rotating blade assembly just above the cup. With this rotating blade assembly and the shroud around the cup, this CDA creates a downward air flow when the blade rotates. This air flow affects the direction of droplets, forcing them to travel toward the target plant.

Insecticides. An emulsifiable concentrate (EC) formulation of diazinon with $4 \mathrm{lb}$ a.i. per gal (0.47 kg.iter-1) was applied by hydraulic and CDA sprayers at a rate of 1 pint/acre $(1.2$ liters/ha) of formulated product . Clean Crop Diazinon 500-AG (Platte Chemical Co., Fremont, Neb. ) was used in 1989 and DZN AG500 4EC (CibaGeigyCorp., Greensboro, N. C.) was used in 1991. Malathion 57EC (Platte Chemical Co.), which contains $5.7 \mathrm{lb}$ a.i./gal (0.68 kg.literl), was applied at a rate of 2 pints/acre (2.4 liters/ha) in 1990. An experimental systemic aphicide, RH-7988 25\% wettable powder (Rohm \& Haas Co.,
Philadelphia), was used in one treatment in 1991 at a rate of $0.24 \mathrm{lb} /$ acre $(0.27 \mathrm{~kg} / \mathrm{ha})$ of formulated product, mixed with an oil carrier (Clean Crop Spray Oil 6E, Platte Chemical Co. ) at 1 quart/acre (2.34 liters/ha).

Insecticides applied by the electrostatic sprayer were mixed in $1 \mathrm{gal} /$ acre (9.4 liters/ha) of a vegetable oil carrier (Prime Oil, Riverside/Terra Corp., Sioux City, Iowa) and were evaluated at lower than the standard rates used with the hydraulic sprayer. In 1990, a one-half rate (1 pint/acre) and a one-quarter rate ( 0.5 pint/acre ) of malathion were evaluated. In 1991, the full rate (1 pint/acre) and onequarter rate (0.25 pint/acre) of diazinon were evaluated.

Aphid evaluation. Green peach aphid, Myzus persicae, was the dominant species in all trials but was found potato aphid [Macrosiphum eupbovbiae (Thomas)] in collard and lettuce plots mixed with other species, including

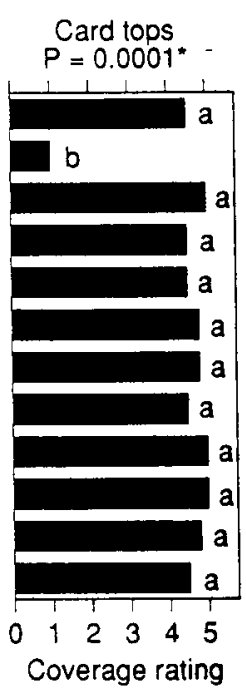

Fig. 1. Results of treatment with diazinon applied by various nozzles and pressures on collards (Trial 1) and red leaf lettuce (Trial 2) at Willard, Ohio, 1989: mean aphid density 3 or 4 days after treatment (DAT), and mean ratings of coveragee on water sensitive spray cards in the canopy. Within eacb grapb, means followed by tbe same letter are not signicantly different $(\mathrm{P}>0.05) ; \mathrm{P}$. probability value for treatment effect from ANOVA. Treatment abbreviations: cone $\mathrm{DC}=$ disc-cove hollow cone; coneIP $=$ one-piece hollow cone; twin =twin flat fan; flat $80=80^{\circ}$ standard flat fan; flat $110=110^{\circ}$ standard flat fan; over = directed over vow; drop= directed on drop pipes; broad = broadcast. Equivalents: 60 psi $=414 \mathrm{kPa}$; $100 \mathrm{psi}=690 \mathrm{kPa} ; 200 \mathrm{psi}=$ $1380 \mathrm{kPa}$.

in 1989 and mustard greens plots in 1990 and turnip aphid [Lipaphis erysimi (Kaltenbach)] in turnip greens plots in 1991. Aphids were evaluated on randomly selected plants near the center of each plot 2 to 4 days after treatment, and in some trials again 7 to 14 days after treatment. Times of aphid evalu- 
ation and number of plants evaluated are shown in Table 1. In Trial 1, aphid densities on the bottom and top leaf surfaces of four collard plants per plot were rated in each of three zones: the lower zone included thick, old leaves in the lower plant canopy (mean $=4$ old leaves/plant); the middle zone included large, thin leaves (mean = $10 /$ plant); and the upper zone included small, young leaves (mean $=3$ / plant). Aphid densities in each zone were recorded in seven categories: $0=$ no aphids, $1=1$ to 4 aphids, $2=5$ to 11 aphids, $3=12$ to 33 aphids, $4=34$ to 100 aphids, $5=101$ to 300 aphids, and $6=301$ to 900 aphids per zone, similar to the system used by Wright and Wheatley ( 1952 ). In Trials 2 to 5, aphids were counted on 4 to 20 plants / plot. In Trial 6, aphids were counted on one lower, one middle, and one upper leaf per plant rather than on entire plants because aphid density was extremely high.

Spray coverage and drift evalu ation. Moisture-sensitive spray cards (Spraying Systems Co.) were placed in the canopy to measure relative spray coverage. Water-sensitive cards were used for treatments applied by hydraulic and CDA sprayers, and oil-sensitive cards were used for electrostatic treatments. In Trial 1, four cards [each $3 \times$ 2 inch $(76 \times 52 \mathrm{~mm})$ ] were clipped to each of two randomly selected collard plants near the center of each plot; on each plant, one card was clipped on top and one on the bottom of a leaf in the upper canopy and likewise on a lower canopy leaf. The procedure was modified for later trials to avoid problems with dew and leaves too weak to support cards; narrower cards [3 $x 1$ inch (76 $x 26 \mathrm{~mm})$ ]were clipped on 6inch $(15-\mathrm{cm})$ metal or plastic stakes inserted into soil in the crop canopy. Two cards were placed back to back on each stake, one card facing up and one facing down, thus simulating the top and bottom leaf surfaces. One stake

Fig. 2. Results of treatment with malathion applied by various nodes and pressures on mustard greens (Trials 3 and 4) at Willard, Ohio, 1990: mean aphid density 2 to 12 days after treatment (DAT), mean ratings of coverage on moisture sensitive spray cards in the canopy, and mean drift? ratings. Within each graph, means followed by the same letter are not significantly different $(P>$ $0.05) ; P=$ probability value for treatment effect from ANOVA.

Treatment abbreviations: cone $=$ disc-cove hollow cone; $C D A=$ controlled droplet applicator; twin $=$ twin flat-fan; $1 / 2=$ half-rate of malathion; $1 / 4=$ quarterrate of malathion; over $=$ directed over row; drop = directed on drop pipes; broad = bvoadcast. Equivalents: 60 psi. 414 $\mathrm{kPa} ; 150$ psi. $1035 \mathrm{kPa}$.
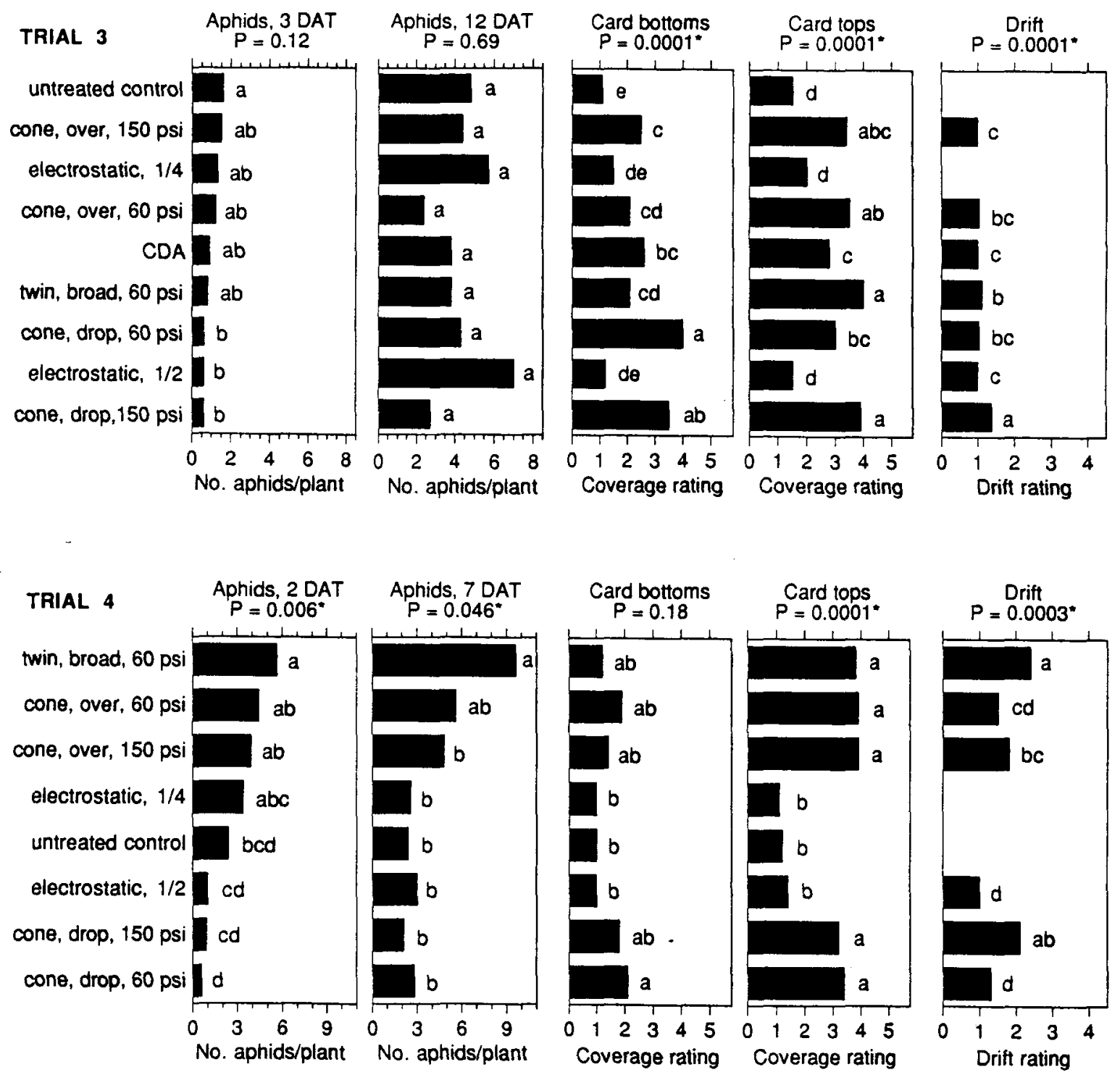

HortTechnology • Oct./Dec. 1995 5(4) 
per lettuce plot was used in 1989 and two stakes per mustard plot in 1990, with all stakes inserted at a $45^{\circ}$ angle. In 1991, stakes were positioned at $30^{\circ}$ and $60^{\circ}$ angles within the crop canopy, with three stakes per angle per plot. Cards placed at $30^{\circ}$ simulated old leaves while $60^{\circ}$ cards simulated young or middle aged leaves.

Drift was assessed in Trials 3 to 6 by stapling moisture-sensitive cards ( 3 $¥ 2$ inch) to wood posts oriented vertically at $6 \mathrm{ft}(1.8 \mathrm{~m})$ from the downwind edge of each plot. Cards were stapled at heights of $1 \mathrm{ft}(0.3 \mathrm{~m}), 3 \mathrm{ft}$ $(0.9 \mathrm{~m})$, and $5 \mathrm{ft}(1.5 \mathrm{~m})$ above ground and oriented vertically. In Trials 3 and 4 , posts were also placed $12 \mathrm{ft}(3.7 \mathrm{~m})$ from plot edges. One set of drift cards was evaluated for each plot.

After each trial, cards were mounted on paper, laminated in plastic, and rated on a scale from one to five. For cards in the canopy, a card with no detectable coverage was rated one; a card with fine and scarce droplets was rated two, a card with fine droplets but with irregular coverage was rated three, a card with ideal coverage or fine droplets evenly distributed was rated four, and a card with coalescent droplets was rated five. Cards used for evaluating drift were also rated on a scale from one to five; a card with no visible deposit was rated one and a card with many droplets was rated five.

Statistical analysis. Data on aphid density, canopy coverage, and drift were subjected to analysis of variance (ANOVA), with treatment and block as main effects, using SAS's general linear models procedure (SAS Institute, 199 1); analysis included mean separation by least significant difference (LSD) $t$ tests, and nonorthogonal single degree of freedom contrasts. In nonorthogonal contrasts, the hydraulic boom treatment with hollow cone nozzles directed over rows at 60 psi was defined as a standard treatment with which other treatments were compared. In Trials 1 and 6, aphid ratings were analyzed with leaf zone nested within treatment as an additional main effect. In Trials 3 to 6, drift analysis included height and distance as additional factors, and in Trials 5 and 6, spray coverage analysis included angle as an additional factor. Relationships between aphid densities and spray card ratings on bottom surfaces of cards were evaluated by SAS's correlation analysis.

\section{Results}

Aphid control. Results of aphid control are shown by treatment in Fig. 1 for Trials 1 and 2, Fig. 2 for Trials 3 and 4 , and Fig. 3 for Trials 5 and 6. A summary of treatment contrasts for aphid control in all six trials is shown in Table 3. Aphid populations varied among trials, from low density in Trials 3 and 4 , to moderate density in

Fig. 3. Results of treatments applied by various nozzles and pressures on turnip greens (Trials 5 and 6) at Columbus, Ohio, 1991: mean aphid density-2 to 14 days after treatment (DAT), mean ratings of coverage on moisture sensitive spray cards in the canopy, and mean drift ratings. In Trial 5, the treatment at bottom of graph was with $\mathrm{RH}-7988$ insecticide; all others except controls were treated with diazinon. Within each graph, means followed by the same letter are not significantly different $(P>0.05)$; P. probability valve for treatment effect from ANOVA. Treatment abbreviations: cone $=$ disc-cove hollow cone; flat $=80^{\circ}$ standard flat fan; twin = twin flat fan; $C D A=$ controlled droplet applicator; full $=$ full rate of diazinon; $1 / 4=$ quarterrate of diazinon; over $=$ directed over vow; drop = directed on drop pipes; broad = broadcast. Equivalents: 60 psi $=414$ $\mathrm{kPa} ; 150$ psi. $1035 \mathrm{kPa}$.
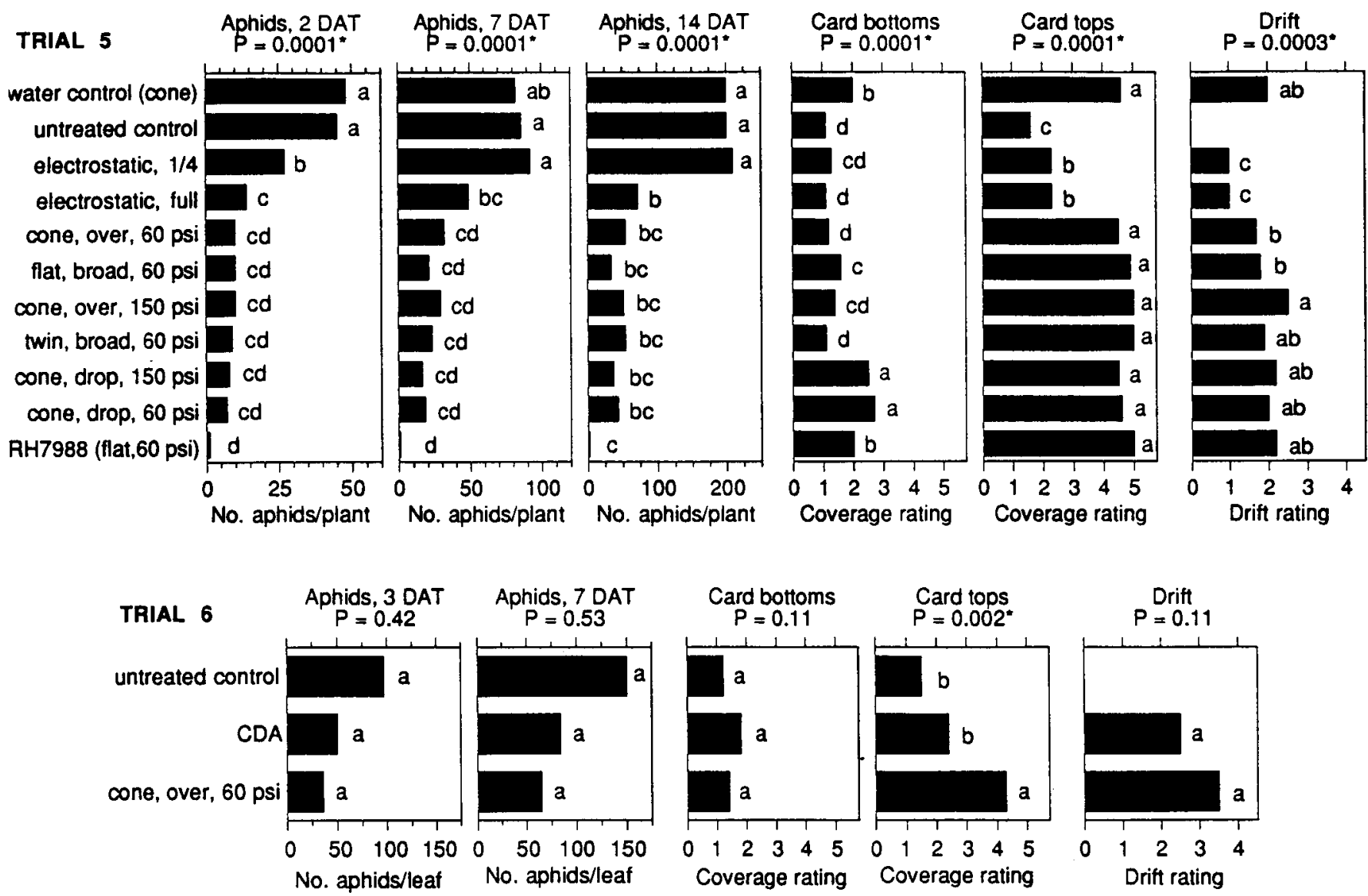
Trials 1, 2, and 5, to high density in Trial 6. Mediocre aphid control was achieved with diazinon or malathion in all trials whether populations were low or high; aphid density in many insecticide-treated plots was higher than in untreated plots. Data on aphid distribution within plants was documented in Trial 1; aphids were most dense on the undersides of the lowest leaves and nearly as dense on the undersides of middle leaves; few aphids were found on either side of the upper leaves, and intermediate densities of aphids were found on the tops of lower and middle leaves.

The factor that most often led to differences in aphid densities among treatments was nozzle position. The expected trend of significantly better aphid control from nozzles on drop pipes than from nozzles directed over rows was shown in Trials 3 and 4 (Table 3). This trend was not seen in Trials 1,2 , or 5 , in which there was no difference on aphid control when comparing nozzles over rows with nozzles on drop pipes.

Varying the pressure used with hollow cone nozzles did not significantly affect aphid control in any of our trials. Aphid control on bottom leaf surfaces was no different among the three pressures from 60 to 200 psi compared in Trials 1 and 2 or between the relatively low pressure of 60 psi and relatively high pressure of 150 psi compared in Trials 3,4, or 5 (Table 3).

Nozzle type did not significantly affect aphid density in any of our trials, as summarized in Table 3. Diazinon or malathion applied by hollow cone nozzles positioned over rows did not control aphids differently than by twin flat fans in Trials $1,2,3,4$, or 5 . Hollow cone nozzles over rows did not control aphids differently than standard flat fans in Trials 1,2, or 5. Aphid densities were not significantly different when sprayed with diazinon by twin flat fans compared to flat fans in Trials 1,2 , or 5 or by $80^{\circ}$ flat-fans compared to $110^{\circ}$ flat fans in Trials 1 and 2. Application by disc-core hollow cones did not control aphids differently than by one-piece hollow cones when directed over rows or on drop pipes in Trials 1 or 2 . In Trial 5, aphids were reduced to the lowest density in the treatment with systemic WI-7988; despite the good control, flat-fan nozzles did not control aphids signifi- cantly better when applying RE-7988 than when flat fans were used to apply diazinon when evaluated after 2, 7, and 14 days (Fig. 3).

The CDA produced results comparable to the standard hydraulic boom sprayer treatment with hollow cone nozzles over rows at 60 psi in Trial 3 (Fig. 2). Aphid control by the CDA appeared to be poorer but was statistically no different than by hollow cones in Trial 6 (Fig. 3).

Whether or not aphid control with an electrostatic sprayer was significantly different than a hydraulic boom sprayer with hollow cones directed over rows varied among trials and depended on whether a full rate or a reduced rate of insecticide was used with the electrostatic sprayer. In Trial 3, aphid density after 3 days and again after 12 days was no different where the electrostatic sprayer applied either the one-halfrate or one-quarter-rate of malathion than where malathion was applied at the fill rate by hollow cones directed over rows at 60 psi (Fig. 2). In Trial 4, aphid density 2 days after application was significantly lower where the onehalf-rate of malathion was delivered by the electrostatic sprayer than by the

Table 3. Effect of specific treatments on reducing aphid density, tested by nonorthogonal single degree of freedom contrasts.

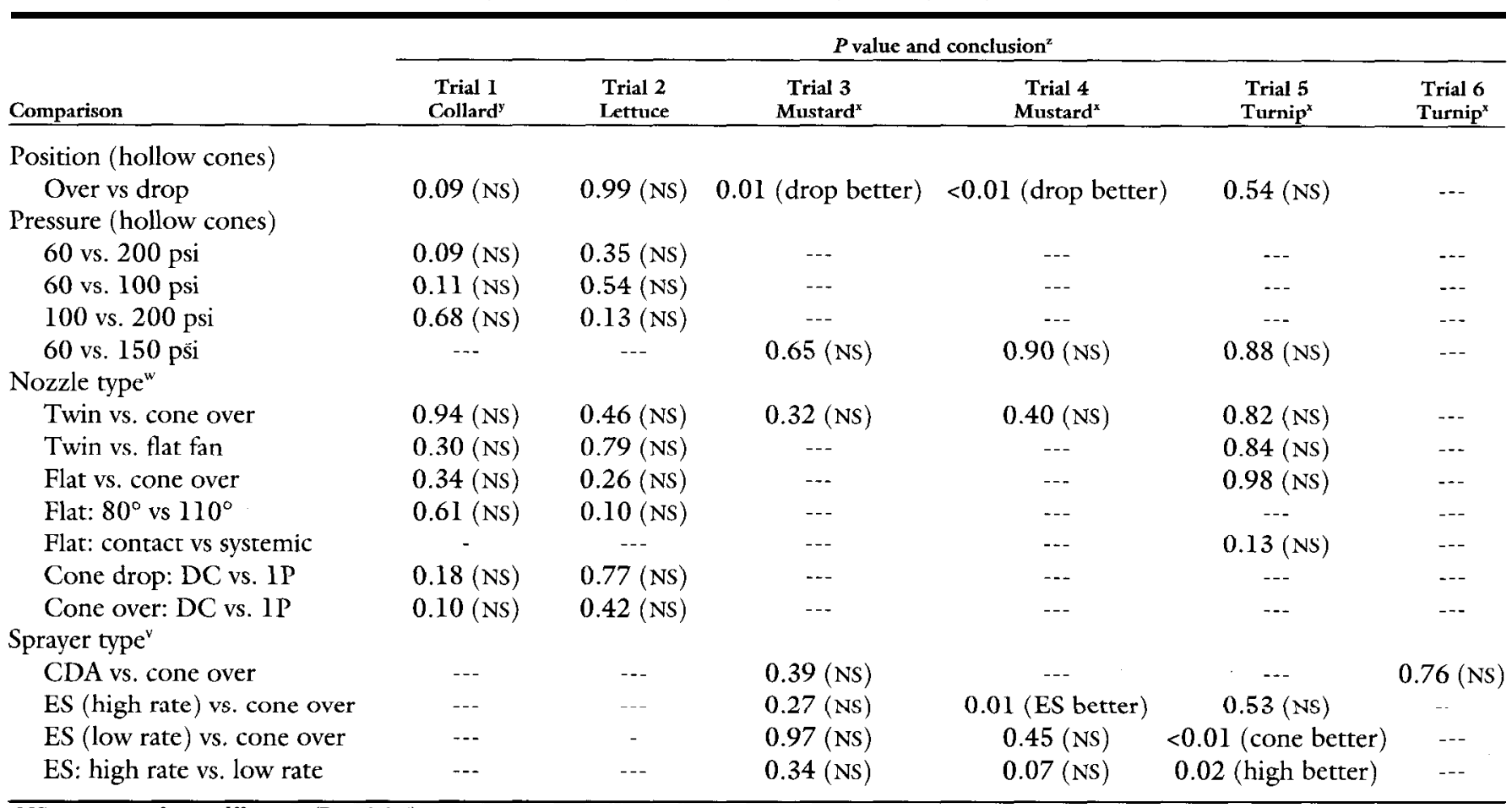

${ }^{2} \mathrm{NS}=$ no significant dfference $(P>0.0 .5)$.

${ }^{y}$ For collards, based on leaf bottoms only.

${ }^{x}$ Based on first evaluation date only.

${ }^{2}$ Cone = disc-cove bellow cone at $60 \mathrm{psi}(414 \mathrm{kPa}) ;$ twin = twin flat fan; flat = standard flat fan (contact = diazinon insecticide; systemic = RH-7988 insecticide); $D C=$ disc-core hollow cone; $1 P=$ one-piece hollow cone .

${ }^{\circ} \mathrm{CDA}=$ controlled droplet applicator; ES = electrostatic (high = high rate of insecticide; low = low rate of insecticide). 
full rate with the standard hydraulic cones over rows, but this effect was lost by the 7-day aphid evaluation (Fig. 2). When the full rate of diazinon was used in Trial 5, aphid density after treatment by the electrostatic sprayer was not significantly different than treatment by hollow cones over rows, when evaluated after 2,7 , or 14 days (Fig. 3), but electrostatic treatment with the one-quarter-rate of diazinon resulted in aphid density significantly higher than where diazinon was applied at the full rate with hollow cones over rows, after 2, 7, or 14 days (Fig. 3).

Spray coverage. Ratings for coverage of moisture-sensitive cards by spray deposits in the crop canopy are shown by treatment in Fig. 1 for Trials 1 and 2, Fig. 2 for Trials 3 and 4, and Fig. 3 for Trials 5 and 6. A summary of treatment contrasts for coverage in all six trials is shown in Table 4.

Coverage of bottom surfaces (i.e., downward-facing cards) was affected by nozzle position, but results were inconsistent among trials. Contrasts showed the expected trend of hollow cone nozzles providing significantly better coverage when on drop pipes than when over rows in Trials 3 and 5 but the unexpected opposite trend of significantly better control when over rows than on drop pipes in Trial 1 (Table 4).
Pressure used with hollow cone nozzles did not affect coverage in Tri-als 3,4 , or 5 but affected coverage in Trials 1 and 2; contrasts showed that coverage on bottom surfaces was significantly better in the 100-psi treatments than in the 60-psi treatments in Trial 1, and coverage was better in the 200-psi treatments than in the 100-psi treatments in Trial 2 (Table 4).

Coverage was not significantly affected by nozzle type in most trials. The standard treatment of hollow cone nozzles positioned over rows provided coverage no different than twin flat fans in Trials 1, 3,4, and 5, but coverage in Trial 2 was significantly better by cones directed over rows than by twin flat fans (Table 4). Bottom-surface coverage provided by standard flat fans was no different than by hollow cone nozzles over rows or by twin flat fans in Trials 1 or 2 , but flat fans covered significantly better than hollow cones and than twin flat fans in Trial 5. Coverage by $80^{\circ}$ flat fans was not significantly different than by $110^{\circ}$ flat fans in Trials 1 and 2. Coverage was not significantly different in disc-core hollow cone treatments compared with one-piece hollow cone treatments in Trial 1 (Table 4).

The CDA provided coverage comparable to the standard hydraulic boom sprayer treatment with hollow cone nozzles over rows at 60 psi in Trial 3 (Fig. 2) and in Trial 6 (Fig. 3). A difference in coverage by the CDA was the pattern of droplet deposition, which was in streaks rather than spots.

Coverage with an electrostatic sprayer was not significantly different than with a hydraulic boom sprayer with hollow cones directed over rows in Trials 3 and 5, but, in Trial 4, coverage was significantly better in the hollow cone treatment than in electrostatic treatments (Table 4).

When the influence of card angle was evaluated in Trial 5, we found that coverage of bottom surfaces was significantly affected by angle $(\mathrm{P}=$ 0.0001 ). Bottoms of $60^{\circ}$ cards, which simulated younger leaves, were significantly better covered than bottoms of $30^{\circ}$ cards, which simulated older leaves; top surface coverage was not affected by angle in Trial $5(\mathrm{P}=0.18)$. In Trial 6 , spray droplet deposition again was significantly influenced by card angle for bottom surfaces $(\mathrm{P}=0.003)$ but not for top surfaces $(P=0.24)$; bottoms of $60^{\circ}$ cards were covered significantly better than bottoms of $30^{\circ}$ cards.

Spray coverage vs. aphid density. There was a weak negative correlation between aphid density and spray coverage of bottom surfaces of cards; high coverage ratings were associated with low aphid densities. Whether ana-

Table 4. Effect of specific treatments on coverage of the bottom side of moisture-sensitive spray cards in the crop canopy, tested by nonorthogonal single degree of freedom contrasts.

\begin{tabular}{|c|c|c|c|c|c|c|}
\hline \multirow[b]{2}{*}{ Comparison } & \multicolumn{6}{|c|}{$P$ value and conclusion ${ }^{2}$} \\
\hline & $\begin{array}{l}\text { Trial l } \\
\text { collard }\end{array}$ & $\begin{array}{l}\text { Trial } 2 \\
\text { lettuce }\end{array}$ & $\begin{array}{c}\text { Trial 3 } \\
\text { mustard }\end{array}$ & $\begin{array}{c}\text { Trial } 4 \\
\text { mustard }\end{array}$ & $\begin{array}{l}\text { Trial } 5 \\
\text { turnip }\end{array}$ & $\begin{array}{l}\text { Trial } 6 \\
\text { turnip }\end{array}$ \\
\hline \multicolumn{7}{|l|}{ Position (hollow cones) } \\
\hline Over vs. drop - & 0.02 (over better) & 0.17 (NS) & $<0.01$ (drop better) & 0.38 (NS) & $<0.01$ (drop better) & -.. \\
\hline \multicolumn{7}{|c|}{ Pressure (hollow cones) } \\
\hline 60 vs. 200 psi & 0.07 (NS) & 0.23 (NS) & -.. & --- & $-\cdots$ & --- \\
\hline 60 vs. 100 psi & $0.03(100$ & 0.33 (NS) & --- & --- & $\cdots$ & --- \\
\hline 100 vs. $200 \mathrm{psi}$ & $1.00(\mathrm{NS})$ & 0.03 (200 psi better) & --- & $\cdots$ & $-\cdots$ & --- \\
\hline 60 vs. 150 psi & --- & 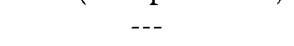 & 0.83 (NS) & $0.22(\mathrm{NS})$ & $0.65(\mathrm{NS})$ & --- \\
\hline \multicolumn{7}{|l|}{ Nozzle type $e^{x}$} \\
\hline Twin vs. cone over & 0.20 (NS) & 0.04 (cone better) & 1.00 (NS) & 0.22 (NS) & 0.84 (NS) & --- \\
\hline Twin vs. flat fan & 0.85 (NS) & 0.55 (NS) & -- & -- & 0.02 (flat better) & --- \\
\hline Flat vs. cone over & 0.19 (NS) & 0.08 (NS) & --- & --- & 0.03 (flat better) & --- \\
\hline Flat: $80^{\circ}$ vs. $110^{\circ}$ & $0.74(\mathrm{NS})$ & 0.30 (NS) & --- & --- & $-\ldots$ & --- \\
\hline Cone drop: DC vs. $1 P$ & 0.51 (NS) & $1.00(\mathrm{NS})$ & --- & --- & $\therefore$ & --- \\
\hline Cone over: DC vs. IP & $0.11(\mathrm{NS})$ & 0.04 (1P better) & -.- & --- & -- & -- \\
\hline \multicolumn{7}{|l|}{ Sprayer type ${ }^{\mathrm{w}}$} \\
\hline CDA vs. cone over & $\cdots$ & --- & 0.23 (NS) & $\cdots$ & --- & 0.10 (NS) \\
\hline ES vs. cone over & -.- & --- & 0.08 (NS) & 0.05 (cone better) & $0.88(\mathrm{NS})$ & --- \\
\hline
\end{tabular}

${ }^{\mathrm{z}} \mathrm{NS}=$ no significant difference $(P>0.05)$

${ }^{\gamma}$ For collards, based on lower canopy only.

${ }^{x}$ Cone $=$ disc-core hollow cone at $60 \mathrm{psi}(414 \mathrm{kPa}) ;$ twin = twin flat fan; flat = standard flat fan; $D C=$ disc-core hollow cone; IP = one-piece hollow cone.

${ }^{2} \mathrm{CDA}=$ controlled droplet applicator; $E S$ = electrostatic. 
Table 5. Effect of specific treatments on drift to vertically mounted moisture-sensitive spray cards, tested by nonorthogonal single degree of freedom contrasts.

\begin{tabular}{|c|c|c|c|c|}
\hline \multirow[b]{2}{*}{ Comparison } & \multicolumn{4}{|c|}{$P$ value and conclusion ${ }^{x}$} \\
\hline & $\begin{array}{c}\text { Trial 3 } \\
\text { mustard }\end{array}$ & $\begin{array}{c}\text { Trial } 4 \\
\text { mustard }\end{array}$ & $\begin{array}{l}\text { Trial 5 } \\
\text { turnip }\end{array}$ & $\begin{array}{l}\text { Trial } 6 \\
\text { turnip }\end{array}$ \\
\hline \multicolumn{5}{|l|}{ Position (hollow cones): } \\
\hline Over vs. drop & $<0.01$ (over better) & 0.66 (NS) & $1.00(\mathrm{NS})$ & $\ldots$ \\
\hline \multicolumn{5}{|l|}{ Pressure (hollow cones) } \\
\hline 60 vs. 150 psi & $<0.01$ ( 60 psi better $)$ & $<0.01$ ( 60 psi better) & 0.03 (60 psi better) & --- \\
\hline \multicolumn{5}{|l|}{ Nozzle type $e^{y}$} \\
\hline Twin vs. cone over & 0.16 (NS) & $<0.01$ (cone better) & 0.42 (NS) & -- \\
\hline Twin vs. flat & $\ldots$ & -- & $0.59(\mathrm{NS})$ & -- \\
\hline Flat vs. cone over & $\ldots$ & --- & 0.79 (NS) & -- \\
\hline \multicolumn{5}{|l|}{ Sprayer type $\mathrm{e}^{\mathrm{x}}$} \\
\hline CDA vs. cone over & 0.48 (NS) & --- & 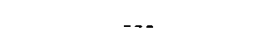 & $0.11(\mathrm{NS})$ \\
\hline ES vs. cone over & 0.48 (NS) & $0.08(\mathrm{NS})$ & 0.02 (ES better) & -- \\
\hline
\end{tabular}

NS $=$ no significant difference $(P>0.05)$

${ }^{y}$ Cone $=$ disc-core hollow cone at $60 \mathrm{psi}(414 \mathrm{kPa}) ;$ twin $=$ twin flat-fan; flat = standard flat-fan .

${ }^{x} \mathrm{CDA}=$ controlled droplet applicator; $\mathrm{ES}=$ electrostatic.

lyzed by treatment or with treatments pooled, correlations were statistically insignificant for almost all data sets. For analysis with treatments pooled, and with the first aphid rating if aphids were rated more than once, Pearson correlation coefficients $(r)$ were -0.12 $(P=0.48)$ in Trial 1 (for aphids on bottom of lower leaves only, and for cards in lower canopy only); $0.61(\mathrm{P}=$ $0.39)$ in Trial $2 ;-0.13(\mathrm{P}=0.51)$ in Trial 3; $-0.31(\mathrm{P}=0.08)$ in Trial 4; $0.12(\mathrm{P}=0.44)$ in Trial 5; and $-0.38(\mathrm{P}$ $=0.23$ ) in Trial 6 (for the middle leaf zone only).

Drift. Ratings for drift on moisture-sensitive cards placed downwind of treated plots are shown by treatment in Fig. 2 for Trials 3 and 4 and Fig. 3 for Trials 5 and 6. A summary of treatment contrasts for drift in all four trials is shown in Table 5. Drift from treated plots to vertically mounted spray cards was consistently affected by pressure; in Trials 3,4, and 5, there was significantly less drift when treatments were applied at 60 psi than at 150 psi. Drift was affected by nozzle position in Trial 3, where there was significantly less drift from nozzles directed over rows than from nozzles on drop pipes directed sideways between rows. Drift was not affected by nozzle position in Trials 4 or 5 . Nozzle type did not significantly affect drift inmost comparisons; one exception was significantly less drift from hollow cones over rows than from twin flat fans in Trial 4, but this did not occur in Trials 3 or 5. Drift from the CDA was not significantly different than that from the hydraulic sprayer with hollow cones directed over rows in Trials 3 and 6 . Drift from the electrostatic sprayer was not significantly different than from the hydraulic sprayer with hollow cones directed over rows in Trials 3 and 4, but, in Trial 5, drift was significantly less from the electrostatic sprayer than from the standard hydraulic treatment (Table 5).

Drift was significantly affected by height above ground in Trial $5(\mathrm{P}=$ $0.0001)$ and Trial $6(P=0.0002)$, where drift was greater at 1 and $3 \mathrm{ft}$ high than at a 5-ft high, but height had no effect on drift in Trial $3(\mathrm{P}=0.46)$ or Trial $4(\mathrm{P}=0.33)$. Drift was not significantly affected by distance from plots under the fairly calm weather conditions of Trial $3(\mathrm{P}=0.19)$ but was affected under the breezier conditions of Trial $4(\mathrm{P}=0.04)$, when drift was significantly greater at $6 \mathrm{ft}$ than at $12 \mathrm{ft}$ from plots.

\section{Discussion}

In all of our trials, hollow cones tested at relatively high pressures of 150 to 200 psi vs. a relatively low pressure of 60 psi did not differ significantly in aphid control. This lack of difference is advantageous because it shows that relatively low spray pressure, with consequently less drift, can be used without losing aphid control capabilities. Low crop height in Trials 3 and 5 may explain the lack of aphid control differences due to pressure, but high pressure-did not result in better control than low pressure even in the taller crops of Trials 1 , 2 , and 4 . Increased pressure provided better control of tobacco budworm by Mistric and Smith ( 1971 ) and cabbage caterpillars by Workman (1983), but associated drift was not reported in these studies.

Placing hollow cone nozzles on drop pipes directed sideways at the canopy controlled aphids significantly better with malathion than when nozzles were directed over rows in Trials 3 and 4. Drop nozzles were better than nozzles over tops for beet armyworm control in cotton (Womac et al., 1992), for Colorado potato beetle control in potatoes (Zehnder and Speese, 1991), and for caterpillar control in cabbage (Workman, 1983).

Despite the known differences in spray patterns produced by different types of nozzle tips, we saw surprisingly little difference in aphid control in the field among treatments with different nozzle types. Although hollow cones were slightly better than flat fans at covering bottom surfaces in the canopy, they did not differ from flat fans in amount of drift produced, and aphid control did not differ significantly in any of our three trials where diazinon was applied through flat fans vs. hollow cones. Control with flat fans was better than we expected. Flat fans are most commonly used for spray volume of about $20 \mathrm{gal} / \mathrm{acre}$ (187 liters/ha); the. better-than-expected control may have been due to our use of flat fans to apply $40 \mathrm{gal} / \mathrm{acre}$ (374 liters/ha). When flat fans were used in Trial 5 to apply a systemic insecticide, control better than all other treatments was obtained; this supports our assumption that systemic products depend less on application methods than contact products. Twin flat fans 
did control aphid any differently than either flat fans or hollow cones. Although a taller canopy may give twin flat fans some advantage over flat-fan nozzles, we found no significant difference in aphid control between twinflat-fan and flat-fan treatments in tall crops such as in Trials 1 and 2 or in short crops as in Trial 5. Zehnder and Speese (1991) found that damage by Colorado potato beetle was significantly less when permethrin was applied by hollow cones than by flat fans, but permethrin was an insecticide to which the beetle population was becoming tolerant; damage was not significantly affected by flat-fan vs. hollow cones nozzles when applying two insecticides to which the beetle population was susceptible.

The narrow drop size spectrum produced by a CDA should adequately control insects at smaller volume application rates and with less spray drift (Marer, 1988). In Trials 3 and 6, aphid control was similar when diazinon was applied by a CDA and a conventional hydraulic sprayer with hollow cone nozzles, but slightly less drift was produced by the CDA than by hollow cones. Aphid control with the CDA and hollow cones was poor in Trial 6, possibly because plants were over-mature and aphids well above threshold when they were treated.

Electrostatic sprayers should result in reduced drift, decreased rate of insecticide needed, and increased coverage of bottom leaf surfaces (Matthews, 1992). In our Trials 3 and 4 , half-dosage sprays of malathion delivered by the electrostatic sprayer in 50- $\mu \mathrm{m}$ droplets suppressed aphids initially but control was lost by the second evaluation date. The same trend was seen in Trial 5, even when droplet size increased to $200 \mu \mathrm{m}$. Electrostatic sprays were apparently not penetrating the canopy adequately enough to reach aphids on the underside of leaves. Poor canopy penetration by this electrostatic sprayer on an artificial plant canopy under laboratory conditions was documented by Almekinders et al. (1992). Although aphid control provided by our electrostatic sprayer was not as good as that provided by hydraulic sprayers, we think the electrostatic sprayer warrants continued modification and evaluation because it shows promise for controlling insects acceptably at reduced rates of insecticide and it produced less drift than the other treatments. An electrostatic sprayer might perform well for applying a systemic insecticide such as RH-7988. An electrostatic sprayer performed better than other equipment for caterpillar control on' broccoli (Law and Mills, 1980) and controlled insects as well as conventional treatment on cotton (Manley, 1982).

Our method may have resulted in underestimates of drift, but moisturesensitive spray cards were useful as a crude measure of differences among treatments. Spray cards adequately measure spray deposition in target canopies, but they do not efficiently capture very fine droplets that are a major component of drift. Other methods that are used for detecting residues on leaves or artificial substrates such as fluorescent tracer analysis, neutron activation analysis, and chemical residue analysis (Matthews, 1992) could be used to evaluate drift in experiments such as ours.

We compared canopy coverage with aphid ratings to determine if coverage ratings could be substituted for aphid ratings in future trials, because it is easier to evaluate coverage than aphid mortality. Weak and inconsistent correlations indicated that spray coverage evaluated with mositure-sensitive cards could not adequately substitute for aphid evaluation. It is possible that evaluating coverage with a more quantitative measure, or with other methods such as fluorescent tracer analysis, would correlate better with aphid control. With spray cards or any alternative method, increased sample sizes of target coverage and aphid density may allow stronger and more consistent correlations.

\section{Conclusion}

The desired objective of maximum aphid control, good coverage of upward and downward-facing surfaces in the canopy, and minimum drift was most consistently provided by the hydraulic boom sprayer with hollow cone nozzles on drop pipes directed sideways into the canopy, using the relatively low pressure of 60 psi. The controlled droplet applicator provided control similar to the conventional hydraulic boom sprayer, but with less drift. The electrostatic sprayer used in our trials needs further modification before it can be recommended for applying contact insecticides to control target pests in leaf crop canopies.

\section{Literature Cited}

Almekinders, H., H.E. Ozkan, D.L. Reichard, T.G. Carpenter, and R.D. Brazee. 1992. Spray deposit patterns of an electrostatic atomizer. Trans. Amer. Soc. Agr. Eng. 35:1361-1367.

Cooke, B. K., E.C. Hislop, P.J. Herrington, N.M. Western, and F. Humpherson-Jones. 1990. Air-assisted spraying of arable crops, in relation to deposition, drift and pesticide performance. Crop Protection 9:303-311.

Escallon, E.C. and A.E. Tyner. 1988. Nozzle method and apparatus. U.S. patent no. 4, 4, 749, 125.

Hislop, E.C. 1987. Requirements for effective and efficient pesticide application. In: Brent, K.J. and R.K. Atkin (eds.). Rational pesticide use. Cambridge Univ. Press, Cambridge, England.p, 53-71.

Hey, C., T.A. Koch, T.T. Vaughn, and R.L. Hassell. 1989a. Collard pest control, 1988. Insecticide \& Acaricide Tests 14:111.

Hey, C., TA. Koch, T. T. Vaughn, and R.L. Hassell. 1989b. Control on salad crops, 1988. Insecticide and Acaricide Tests 14: 126-127.

Hay, C. W., T.A. Koch, and R.L. Hassell. 1990. Control of aphids on salad crops, 1989. Insecticide and Acaricide Tests 15:117.

Jeffers, D.L., A.F. Schmitthenner, and D.L, Reichard. 1982. Seed-borne fungi, quality, and yield of soybeans treated with benomyl fungicide by various application methods. Agron. J. 74:589-592.

Law, S.E. and H.A. Mills. 1980. Electrostatic application of low-volume microbial insecticide spray on broccoli plants. J. Amer. Soc. Hort. Sci. 105:774777.

Manley, D. G. 1982. Use of an electrostatic sprayer for cotton insect control. J. Econ. Entomol. 75:655656.

Marer, P.J. 1988. The safe and effective use of pesticides. Univ. of Calif., Statewide Integrated Pest Mgt. Project, Div. of Agr. and Natural Res., Publ. 3324. Univ. of Calif., Oakland.

Matthews, G.A. 1992. Pesticide application methods. 2nd ed. Wiley, New York.

Mistric, Jr., W.J. and F.D. Smith. 1971. Control of tobacco budworm on flue-cured tobacco with insecticides applied mechanically. J. Econ. Entomol. 64:126-132.

Reed, T. 1988. Choosing spray nozzles. Grounds Maintenance 23(5):36, 70.

SAS Institute. 1991. SAS/STAT user's guide. Release 6.03, SAS Inst., Cary, NC.

Womac, A.R., J.E. Mulrooney, and W.P. Scott. 1992. Characteristics of air-assisted and drop-nozzle sprays in cotton. Trans. Amer. Soc. Agr. Eng. 35:1369-1376.

Workman, R.B. 1983. Spray nozzle and pressure tests for cabbage caterpillar control. Proc 10th Intl. Congr. Plant Protection. Lavenham Press, Lavenham, Suffolk, England. p. 509.

Wright, D. W. and G.A. Wheatley. 1952, A comparison of the effectiveness of certain insecticides for the control of the cabbage aphid. 3rd Annu. Rpt. Natl. Veg. Res. Sta., Wellesbourne, Warwick, England. p. 19-27.

Zehnder, G. W. and J. Speese III. 1991. Evaluation of various spray nozzle and volume combinations for control of Colorado potato beetle (Coleoptera: Chrysomelidae) with synthetic and biological insecticides. J. Econ. Entomol. 84: 1842-1849. 